\title{
Call for Proposals
}

\section{Zeitschrift für Psychologie / Journal of Psychology}

The Zeitschrift für Psychologie / Journal of Psychology, originally founded in 1890, is the oldest psychology journal in Europe and the second oldest in the world. Now, reflecting the change in the lingua franca of science from German to English, it is being published completely in English. The Zeitschrift für Psychologie / Journal of Psychology will continue to publish high-quality research from all branches of empirical psychology that is clearly of international interest and relevance - but will now do so in four topical issues per year. For a provisional list, please see below; other topics are in planning.

Each issue generally consists of one broad review paper, accompanied by original articles from leading researchers, all of which are peer-reviewed according to the highest international standards. The subjects covered are determined after consultation within the psychological community.

The Editors and Publisher would welcome proposals for future topical issues. Please submit proposals and suggestions to the Editor-in-Chief at the following address:

Professor Heinz Holling

Fachbereich 07, Psychologie und Sportwissenschaft der Universität Münster

Fliednerstrasse 21

D-48149 Münster

Germany

Tel. +49 $25183-39419$

Fax +49 251 83-39469

E-mail holling@psy.uni-muenster.de
Topics and Guest Editors for 2007:

- Issue 1: Human Memory (Guest Editor: Edgar Erdfelder, Mannheim, Germany)

- Issue 2: Meta-Analysis (Guest Editor: Ralf Schulze, Münster, Germany)

- Issue 3: Self-Regulation (Guest Editors: Bernd Schmitz, Darmstadt, Germany; and Christiane Spiel, Vienna, Austria)

- Issue 4: Adaptive Testing (Guest Editor: Wim van der Linden, Twente, The Netherlands)

\section{Topics and Guest Editors for 2008:}

- Issue 1: Knowledge Communication (Guest Editor: Friedrich W. Hesse, Tübingen, Germany)

- Issue 2: Assessment of Competencies

- Issue 3: To be announced

- Issue 4: To be announced 